\title{
Agrin is highly expressed by chondrocytes and is required for normal growth
}

\author{
Heinz-Juergen Hausser • Markus A. Ruegg • \\ Rolf E. Brenner • Iwona Ksiazek
}

Accepted: 27 November 2006 / Published online: 21 December 2006

(C) Springer-Verlag 2006

\begin{abstract}
Agrin is a heparan sulfate proteoglycan that is best known for its crucial involvement in the organization and maintenance of postsynaptic structures at the neuromuscular junction. Consistent with this role, mice deficient of agrin die at birth due to respiratory failure. Here we examined the early postnatal development of agrin-deficient mice in which perinatal death was prevented by transgenic expression of neural agrin in motor neurons. Such transgenic, agrin-deficient mice were born at Mendelian ratio but exhibited severe postnatal growth retardation. Growth plate morpholgy was markedly altered in these mice, with changes being most prominent in the hypertrophic zone. Compression of this zone was not caused by reduced viability of hypertrophic chondrocytes, as no differences in the apoptosis rates could be observed. Furthermore, deposition of the major cartilage matrix components collagen type II and aggrecan was slightly reduced in these mice. Consistent with a role for agrin in skeletal development, we show for the first time that agrin is highly expressed by chondrocytes and localizes to the growth plate in wild-type mice. Our data show that agrin is expressed in cartilage and that it plays a critical role in normal skeletal growth.
\end{abstract}

H.-J. Hausser $(\bowtie) \cdot$ R. E. Brenner

Department of Orthopedics, Division for Biochemistry

of Joint and Connective Tissue Diseases,

University of Ulm, RKU,

Oberer Eselsberg 45, 89081 Ulm, Germany

e-mail: heinz-juergen.hausser@uni-ulm.de

M. A. Ruegg · I. Ksiazek

Biozentrum, University of Basel, Klingelbergstrasse 50-70,

CH-4056 Basel, Switzerland
Keywords Agrin $\cdot$ Chondrocyte $\cdot$ Growth plate . Skeletal growth

\section{Introduction}

Bone develops via either endochondral or intramembranous ossification, starting with condensation of mesenchymal cells in both situations (Karaplis 2002; Kronenberg 2003). In endochondral ossification, the mechanism by which long bones are formed, there remains a cartilagenous growth plate at the epiphysis which is responsible for longitudinal bone growth. The arrangement of chondrocytes in these growth plates is highly organized, with zones of resting, proliferating, and hypertrophic cells. Bone growth is accomplished mainly by two mechanisms, by proliferation of chondrocytes and by their enlargement when they become hypertrophic. It has been estimated that in mice this process of hypertrophy accounts for approximately $80 \%$ of the total growth rate (Vanky et al. 1998).

It is obvious that proper skeletal bone formation and growth critically depend on a tight regulation of the processes occurring at the growth plate. Both systemic and local factors contribute to this regulation (van der Eerden et al. 2003). Among the locally acting systems the Indian hedgehog/parathyroid hormone-related protein (PTHrP) system and the fibroblast growth factor (FGF) system involving FGF receptor 3 (FGFR3) are the best characterized, but other signaling molecules such as transforming growth factor (TGF)- $\beta$ s, bone morphogenetic proteins (BMPs), and wnt proteins have been shown to contribute, too. Disturbances in these regulatory systems characteristically interfere with normal skeletal development. For example, activating 
point mutations in FGFR3 have been linked in humans to several skeletal dysplasias, including achondroplasia (Rousseau et al. 1994), the most common genetic form of dwarfism in humans, hypochondroplasia (Bellus et al. 1995), and thanatophoric dysplasia (Tavormina et al. 1995). Dwarfism is also an overt phenotype in transgenic mice expressing constitutively active FGFR3 in their growth plates. In these mice, both the hypertrophic and the proliferative zones are significantly smaller than in their littermate controls, though overall histomorphologic architecture of the growth plates is not dramatically altered (Naski et al. 1998).

Agrin is a heparan sulfate proteoglycan that was isolated from basal lamina-rich extracts of the electric organ of the pacific ray Torpedo californica (Nitkin et al. 1987) based on its activity to induce clustering of acetylcholine receptors (AChRs) on cultured muscle cells. Its core protein has a predicted molecular mass of $225 \mathrm{kDa}$ and is composed of protein modules that are also found in other ECM proteins. Importantly, alternative mRNA splicing at several sites gives rise to protein isoforms (Ruegg et al. 1992; Rupp et al. 1992). Alternative splicing at the most carboxy-terminal site, called B in chick and $\mathrm{z}$ in rodents, affects AChR-aggregating activity (Ferns et al. 1993; Gesemannet al. 1995; Ruegg et al. 1992). In particular, only agrin isoforms with amino acid inserts at this $\mathrm{B} / \mathrm{z}$-site (agrin- $\mathrm{B} / \mathrm{z}^{+}$) can induce $\mathrm{AChR}$ aggregation, while isoforms devoid of an amino acid insert (agrin-B/ $/ \mathrm{z}^{-}$) lack this activity. Agrin is crucial for the formation and maintenance of postsynaptic specializations at the neuromuscular junction (NMJ), as agrin mutant mice do not form a proper NMJ and therefore die at birth due to respiratory failure (Gautam et al. 1996; Lin et al. 2001). Similarly, mice that are unable to synthesize agrin- $\mathrm{B} / \mathrm{z}^{+}$and thus only express agrin $-\mathrm{B} / \mathrm{z}^{-}$ also die at birth (Burgess et al. 1999). These experiments are the formal proof that agrin- $\mathrm{B} / \mathrm{z}^{+}$is an essential factor released from motor neurons to induce the formation and maintenance of postsynapses at the NMJ as had been predicted by the agrin hypothesis (McMahan 1990). Agrin's function in the formation of postsynaptic structures requires the muscle-specific kinase MuSK (DeChiara et al. 1996; Glass et al. 1996), which forms an essential component of an agrin receptor complex.

Agrin protein is not confined to the NMJ but is expressed in several tissues including muscle (Lieth et al. 1992), kidney (Groffen et al. 1998), brain (O'Connor et al. 1994) and immune system (Khan et al. 2001). Here we set out to study functions of agrin during early postnatal development outside of the NMJ. To this end, we generated transgenic mice that express agrin$\mathrm{B} / \mathrm{z}^{+}$in motor neurons and mated them with agrin-deficient mice. We show that the resulting transgenic agrin-deficient mice survive but exhibit pronounced postnatal growth retardation. Furthermore, we show that this growth retardation is accompanied by compositional and structural alterations of the growth plate, suggesting functional impairment of the chondrocytes to be responsible for the effects of agrin-deficiency on growth. Moreover, we demonstrate that agrin is expressed by chondrocytes and is deposited in the growth plate. Thus, our experiments establish an unprecedented function of agrin in skeletal growth.

\section{Materials and methods}

Generation of $\mathrm{Tg}_{\mathrm{agrn}}{ }^{-/-}$mice

Rescued agrin-deficient mice that express a basement membrane-bound neural isoform of chick agrin (containing a four amino acid insert at the $\mathrm{A} / \mathrm{y}$ site and an eight amino acid insert at the $\mathrm{B} / \mathrm{z}$ site) under the control of the $9 \mathrm{~kb}$ motor neuron-specific $\mathrm{Hb} 9$ promotor were generated as described elsewhere (I. Ksiazek et al., manuscript in preparation.). In short, mice expressing the transgene were mated with heterozygous agrin-deficient mice (Lin et al. 2001), giving rise to transgenic, heterozygous agrin-deficient offsprings. These mice were again mated with heterozygous agrindeficient mice, yielding homozygous agrin-deficient mice expressing the transgene. Tg/agrn ${ }^{-1-}$ mice lacked all endogenous agrin isoforms but they expressed chick neural agrin in motor neurons.

Chondrocyte cell culture

Chondrocytes were obtained from articular cartilage of 3 -week-old mice by sequential digestion with $0.2 \%$ pronase for $1 \mathrm{~h}$ and $0.025 \%$ collagenase overnight, both in DMEM without addition of fetal bovine serum. Released chondrocytes were cultured in HAM's F-12/ DMEM (1:1) containing 10\% FBS (Biochrom, Berlin). By means of RT-PCR, these cells were shown to express collagen type II, aggrecan, and COMP.

\section{RT-PCR}

Total RNA was extracted from cultured cells using the RNeasy Mini Kit (Qiagen, Hilden, Germany), and digested with RNase-free DNase (Qiagen) to remove any contaminating genomic DNA. cDNA synthesis from total RNA was performed with Omniscript reverse transcriptase (Qiagen) using $(\mathrm{dT})_{15}(1 \mu \mathrm{M})$ and random hexanucleotide primers $(5 \mu \mathrm{M}$; Roche Diagnostics, Mannheim, Germany) simultaneously. 
Aliquots of the cDNAs were incubated with HotStarTaq DNA polymerase (Qiagen) and the primers specified in Table 1. All primers were synthesized by MWG Biotech (Munich, Germany) and were of high purity salt free (HPSF)-quality. The polymerase was activated $\left(15 \mathrm{~min}\right.$ at $\left.96^{\circ} \mathrm{C}\right)$ and then up to 40 cycles $\left(45 \mathrm{~s}\right.$ at $94^{\circ} \mathrm{C}, 45 \mathrm{~s}$ at $60^{\circ} \mathrm{C}, 45 \mathrm{~s}$ at $\left.72^{\circ} \mathrm{C}\right)$ were performed on a RoboCycler Gradient 96 (Stratagene, Amsterdam, The Netherlands). Amplification products were visualized by agarose gel electrophoresis after staining with ethidium bromide. Images were acquired using the ImageMaster VDS system (Amersham Biosciences, Freiburg, Germany) and the accompanying software (version 2.0).

\section{Histological analysis}

Specimens for conventional histological examinations and for immunohistochemistry were fixed in $4 \%$ buffered formaldehyde for at least $72 \mathrm{~h}$. After rinsing with water they were decalcified in $10 \%$ EDTA solution, $\mathrm{pH} 7.4$, for up to 6 weeks. $3.5 \mu \mathrm{m}$ sections were cut from paraffin-embedded tissue and routinely stained with hematoxylin/eosin (HE), safranin O/fastgreen (SO), alcian blue at $\mathrm{pH} 1.0(\mathrm{AB})$, and by the Masson-Goldner (MG) trichrome staining procedure (Goldner 1938).

\section{Immunohistochemistry}

To improve immunoreactivity, deparaffinized samples were incubated for $4 \mathrm{~min}$ at ambient temperature with $1 \mathrm{mg} / \mathrm{ml}$ pronase in $9 \mathrm{mM} \mathrm{CaCl}_{2}, \mathrm{pH} 7.8$ (for the detection of agrin and collagen type $\mathrm{X}$ ); for $30 \mathrm{~min}$ at $37^{\circ} \mathrm{C}$ with $1 \mathrm{mg} / \mathrm{ml}$ pepsin in $0.5 \mathrm{M}$ acetic acid (for the detection of collagen type II); for $30 \mathrm{~min}$ at $37^{\circ} \mathrm{C}$ with 20 munits chondroitinase ABC (Seikagaku, Tokyo) in $50 \mathrm{mM}$ Tris- $\mathrm{HCl}, \mathrm{pH} 8.0$, containing $50 \mathrm{mM}$ sodium acetate and $0.1 \%$ bovine serum albumine, followed by
$10 \mathrm{~min}$ with $2 \mathrm{mg} / \mathrm{ml}$ hyaluronidase (from bovine testis; Sigma, Taufkirchen) in $10 \mathrm{mM}$ sodium citrate, $\mathrm{pH} 6.0$, and $20 \mathrm{~min}$ at $37^{\circ} \mathrm{C}$ with $0.1 \%$ Triton $\mathrm{X}-100$ in PBS (for the detection of aggrecan); and by boiling for $10 \mathrm{~min}$ in $10 \mathrm{mM}$ sodium citrate, $\mathrm{pH} 6.0$ [for the detection of proliferating cell nuclear antigen (PCNA)]. Subsequently the samples were rinsed with phosphate-buffered saline and incubated for $30 \mathrm{~min}$ at ambient temperature with $3 \% \mathrm{H}_{2} \mathrm{O}_{2}$ to inactivate endogenous peroxidase activity. After blocking nonspecific protein binding sites with protein block solution (DAKO, Hamburg), samples were incubated with primary antibody for $2 \mathrm{~h}$ at $37^{\circ} \mathrm{C}$. For immunolocalization of agrin a polyclonal rabbit antiserum raised against the $\mathrm{C}$-terminus of mouse agrin (Eusebio et al. 2003) was used, type $X$ collagen was immunolocalized using the monoclonal antibody X 53 (Girkontaite et al.1996), type II collagen with the monoclonal antibody collagen II Ab-3, clone 6B3 (Lab Vision, Fremont), aggrecan with a polyclonal rabbit anti-aggrecan antibody (Chemicon, Hampshire), and PCNA with the monoclonal antibody PCNA Ab-1, clone PC10 (NeoMarkers, Fremont). Bound mouse antibodies were visualized using the LSAB kit (DAKO) and 3-amino-9-ethylcarbazol (AEC; DAKO) as chromogen according to the instructions of the manufacturer, bound rabbit antibodies were visualized by subsequent incubations with biotinylated goat-anti rabbit antibody (1:1,000; Santa Cruz Biotechnology, Santa Cruz), the streptavidin-conjugated horseradish peroxidase of the LSAB kit, and 3-amino-9-ethylcarbazol as substrate. As a negative control sections were processed in the absence of primary antibody.

Terminal deoxynucleotide transferase-mediated dUTP nick end labeling (TUNEL) assay

For permeabilization, deparaffinized tissue sections were incubated for $8 \mathrm{~min}$ at ambient temperature with $0.1 \%$ Triton $\mathrm{X}-100$ in $4 \mathrm{mM}$ sodium citrate. After

Table 1 Primers used for RT-PCR

\begin{tabular}{|c|c|c|c|c|}
\hline Target & Accesion & $\begin{array}{l}\text { Product } \\
\text { size(s) }\end{array}$ & Upstream primer & Downstream primer \\
\hline$\underset{(14 / 15)}{\text { Agrin }}$ & NM_021604 & 184 & 5'-CAATGAATGCCAGCTGAAGA-3' & 5'-GTGCTGGGAGACAGAGGAAG-3' \\
\hline $\begin{array}{c}\text { Agrin } \\
19 / 20\end{array}$ & NM_021604 & 208,235 & 5'-CATGTGCGATTCTTGGACTTT-3' & 5'-GAGTCCGAGGTCGGTCAATA-3' \\
\hline $\begin{array}{c}\text { Agrin } \\
27 / 29\end{array}$ & NM_021604 & 200,212 & 5'-GGCACCTGGGTTAGGGTATT-3' & 5'-GGATGGCACCATCAAAGC-3' \\
\hline $\begin{array}{r}\text { Agrin } \\
31 / 34\end{array}$ & NM_021604 & $\begin{array}{r}184,208 \\
217,241\end{array}$ & 5'-CAGTGGGGGACCTAGAAACA-3' & 5'-GCCATGTAGTCTGCACGTTCT-3' \\
\hline MuSK & NM_010944 & 193 & 5'-CATTCTGAGCGTGGAAGACA-3' & 5'-TTTGGGGTTACCCATCGTAG-3' \\
\hline GAPDH & NM_001001303 & 73 & 5'-CGTGTTCCTACCCCCAATGT-3' & 5'-TGTCATCATACTTGGCAGGTTTCT-3' \\
\hline
\end{tabular}


washing with PBS, samples were incubated in the dark for $1 \mathrm{~h}$ at $37^{\circ} \mathrm{C}$ with a TUNEL reaction mixture prepared from TUNEL Enzyme (Roche Diagnostics, Penzberg) and TUNEL Label (Roche Diagnostics) according to the instructions of the manufacturer. For positive control, sections were preincubated with DNase I (55 U/ml in $50 \mathrm{mM}$ Tris- $\mathrm{HCl}$, pH 7.5, containing $0.1 \%$ bovine serum albumine) for $10 \mathrm{~min}$ at ambient temperature. Negative controls were incubated with TUNEL Label solution without terminal deoxynucleotide transferase (TUNEL Enzyme). Incorporated fluorescein-labeled dUTP was visualized by fluorescence microscopy.

\section{Image acquisition}

Microscopy was performed with a Zeiss Axioskop 2 microscope (Zeiss, Munich, Germany) equipped with a Zeiss AxioCam MRc digital camera, using the accompanying image acquisition software (AxioVision 3.1).

Roentgenological examination of killed mice was performed using mammography equipment (Senographe DMR, General Electric Healthcare, Solingen) using Kodak MIN-R2000 films. For digitalization images were reproduced to Illford Pan F film (ISO 50) and scanned with a Nikon Super Coolscan 4000 ED film scanner using the SiverFast Ai 6 software.

\section{Results}

Growth retardation of rescued agrin deficient mice

Agrin deficiency in mice leads to perinatal death due to severe impairment of neuromuscular function (Gautam et al. 1996; Lin et al. 2001). As neural agrin released from motor neurons is responsible for proper formation of the $\mathrm{NMJ}$, we decided to generate mice that express full-length chick neural agrin under the control of the promoter of motor neuron-specific homeodomain factor Hb9 (Arber et al. 1999; Thaler et al. 1999). Transgenic mice were selected that expressed the protein in all motor neurons and were mated with heterozygous agrin knockout mice to obtain transgenic agrin mutant mice $\left(\mathrm{Tg}_{\mathrm{agrn}}^{-/-}\right)$ (I. Ksiazek et al., manuscript in preparation). $\mathrm{Tg} \mathrm{agrn}^{-/-}$ mice were born at Mendelian ratio and, in contrast to agrin knockout mice, survived for up to 3 months. However, they were much smaller than their control littermates. While control mice gained approximately $0.5 \mathrm{~g} /$ day in the first 40 days and then continued to grow with a slower growth rate of $0.1 \mathrm{~g} /$ day, the growth of $\mathrm{Tg}_{\mathrm{agrn}} \mathrm{gr}^{-}$mice was reduced by $50 \%$. Moreover, after 4 weeks no further growth could be observed in Tg/agrn ${ }^{-1-}$ mice (Fig. 1).

This growth retardation suggested changes in bone morphology of $\mathrm{Tg}_{\mathrm{agrn}}{ }^{--}$mice. We therefore examined the mice with X-ray and found a shortening of the long bones and the spine, but the bones proper seemed not to be malformed (Fig. 2). The total length of the spine was reduced by approximately $19 \%$ in mice from 2 to 8 weeks of age, femur and tibia were reduced by 15 and $8 \%$, respectively. Because no differences were seen between wild-type mice and heterozygous agrin knockout mice, irrespective of whether they expressed the transgene or not, both were used in the following experiments as controls.

Agrin is expressed by chondrocytes and is deposited into in the growth plate

Since agrin has not been reported to be expressed in skeletal tissue, we next examined expression of agrin in chondrocytes. To this end we first isolated articular cartilage chondrocytes from 3-week-old wild-type mice and looked for agrin expression by RT-PCR using primers specific for mouse agrin that bind in non-alternatively spliced regions. As shown in Fig. 3a, mouse chondrocytes indeed express agrin. Similarly, expression of agrin could also be detected in human articular chondrocytes (data not shown). Though chondrocytes from articular cartilage are not the cells that are responsible for bone growth, this observation

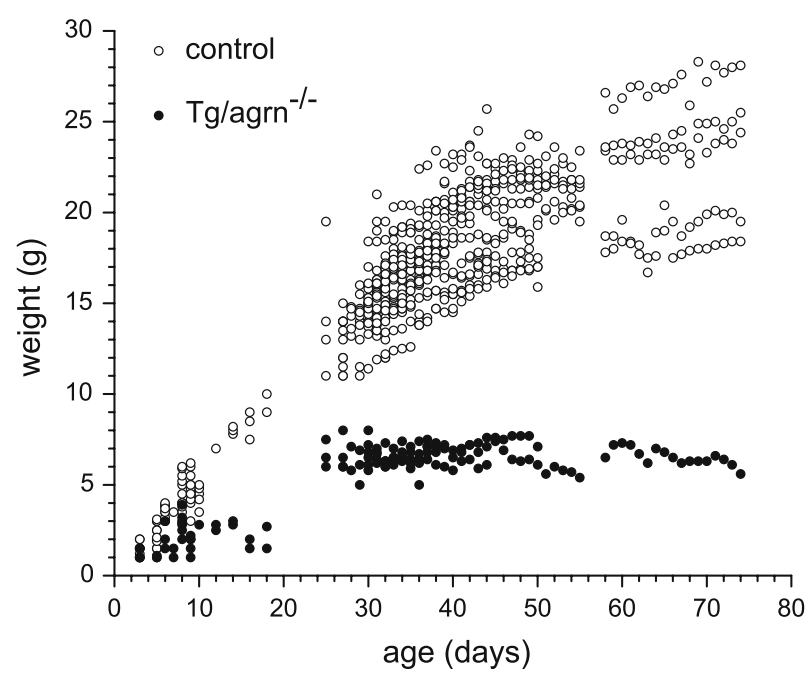

Fig. 1 Growth retardation of $T g /$ agrn $^{-/-}$mice. Growth of control mice (open circles) and Tg/agrn ${ }^{-1-}$ mice (filled circles) was determined by weight measurement. Early postnatal growth was approximately $0.5 \mathrm{~g} /$ day in control mice and $0.25 \mathrm{~g} /$ day in agrindeficient mice. Whereas control mice continued to grow, the growth of $\mathrm{Tg} / \mathrm{agrn}^{-/-}$mice stagnated after 4 weeks 


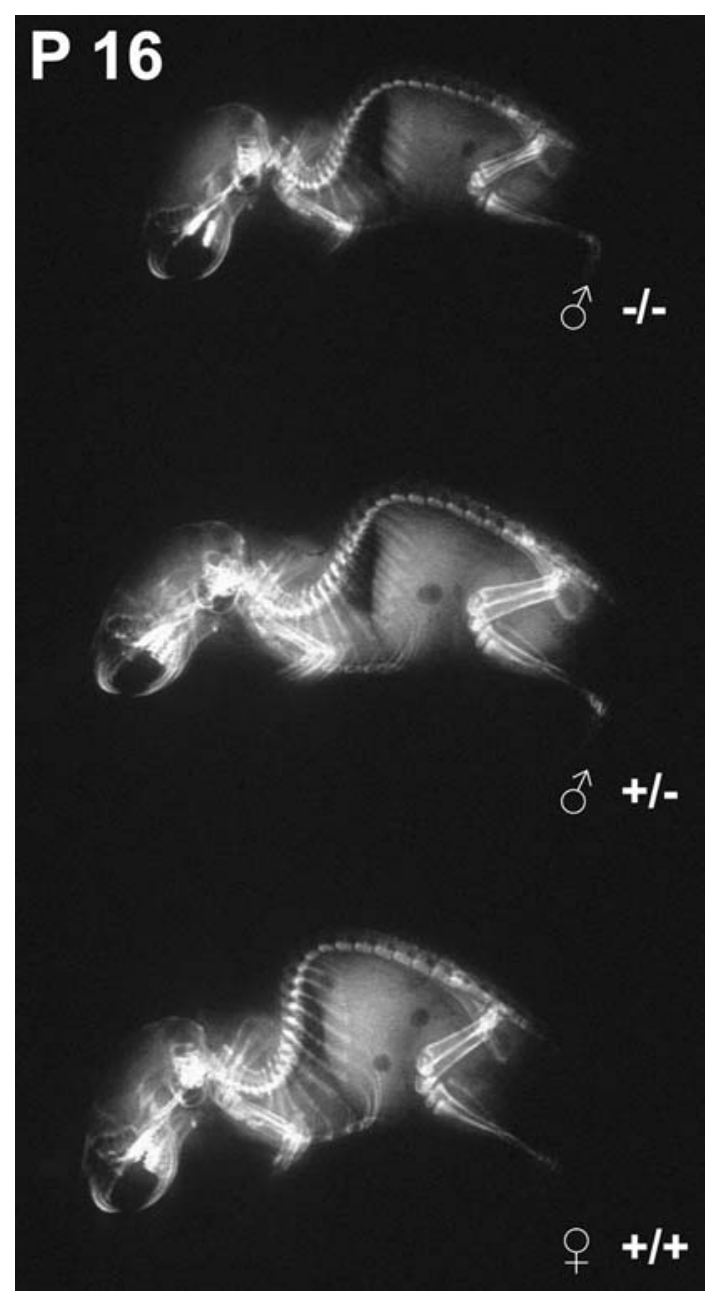

Fig. 2 Shortened bones in $\mathrm{Tg} / \mathrm{agrn}^{-/-}$mice. Roentgenological examination of 16-day-old mice was performed using mammography equipment. $\mathrm{Tg} / \mathrm{agrn}^{-1-}$ mice exhibited shorter long bones and spine, whereas wild-type and heterozygous animals did not differ significantly

suggests that other chondrocytes might express agrin as well.

Bone growth is best characterized in long bones, where longitudinal growth is accomplished mainly by chondrocyte proliferation and hypertrophy in the epiphyseal growth plate. Therefore, we further concentrated on the growth plates of femur and tibia. Immunostaining revealed that agrin was indeed present in femoral growth plates from 4-day-old mice. Staining was predominantly matrix-associated and was most prominent in the zones of proliferating and prehypertrophic chondrocytes, but was also found in the zone of resting chondrocytes (Fig. 3b). No specific staining could be observed in growth plates from $T g /$ agrn $^{-/-}$mice (Fig. 3c). Agrin staining in the growth plate persisted throughout maturation (data not shown).
Growth plate morphology is altered in $\mathrm{Tg}_{\mathrm{agrn}} \mathrm{ag}^{-/}$mice

To evaluate whether agrin deficiency affected the growth plate, we next performed histological analysis of $\mathrm{Tg} / \mathrm{agrn}^{-/}$and control mice at various stages of postnatal development (Fig. 4). At postnatal day 4 (P4), the thickness of the hypertrophic zone was reduced by approximately $30 \%$ in $\mathrm{Tg}_{\mathrm{agrn}}{ }^{-1}$ mice, while the thickness of the proliferative zone was unchanged. This reduction in the size of the hypertrophic zone became more pronounced with age, and at P53 a continuous hypertrophic zone was no longer detectable (Fig. 4m-p). At sites where hypertrophic chondrocytes were still present at this age, the thickness of this "hypertrophic zone" was reduced by approximately $50 \%$. At $\mathrm{P} 4$, we could not detect a difference in safranin- $\mathrm{O}$ and alcian blue stainings (Fig. 4c, g; d, h). However, at P53 both stainings were weaker in $\mathrm{Tg}_{\mathrm{agrn}}{ }^{-/-}$mice (Fig. 4k, o; 1, p), suggesting a decreased glycosaminoglycan content. Furthermore, the weaker Masson-Goldner staining (Fig. 4j, n) in $\mathrm{Tg}_{\mathrm{agrn}}{ }^{-/}$mice indicated a decrease in the collagen content, too.

As the consequence of agrin deficiency was most evident in the hypertrophic zone of the growth plate, we decided to look whether expression of collagen $\mathrm{X}$ is affected in $\mathrm{Tg} / \mathrm{agrn}^{-/-}$mice. This matrix molecule is specifically expressed by hypertrophic chondrocytes and serves as a marker for hypertrophic differentiation. Apart from the already described changes in the thickness of the hypertrophic zone, there was no obvious difference in the matrix staining for collagen $\mathrm{X}$ in 6-day-old $\mathrm{Tg} \mathrm{agrn}^{-1-}$ mice (Fig. 5a, b), indicating proper hypertrophic differentiation. However, we observed a delay in the formation of the secondary ossification center of the proximal tibia (Fig. 5d, e), suggesting a delayed differentiation to hypertrophic chondrocytes.

Matrix composition is altered in $\mathrm{Tg}_{\mathrm{agrn}} \mathrm{ag}^{-1}$ growth plates

The histochemical stainings described above indicated that growth plates from $\mathrm{Tg} / \mathrm{agrn}^{-1-}$ mice might contain reduced amounts of collagen and glycosaminoglycans. As such alterations would suggest functional impairment of growth plate chondrocytes in $\mathrm{Tg}_{\mathrm{agrn}}{ }^{-/}$mice, we specifically looked for matrix deposition of the major cartilage matrix components, collagen type II and aggrecan. Immunohistochemical analysis demonstrated that both, collagen type II and aggrecan, were indeed slightly reduced in the growth plates of $\mathrm{Tg} / \mathrm{agrn}^{-/-}$mice (Fig. 6a, b) already at an early postnatal stage. A reduction in 

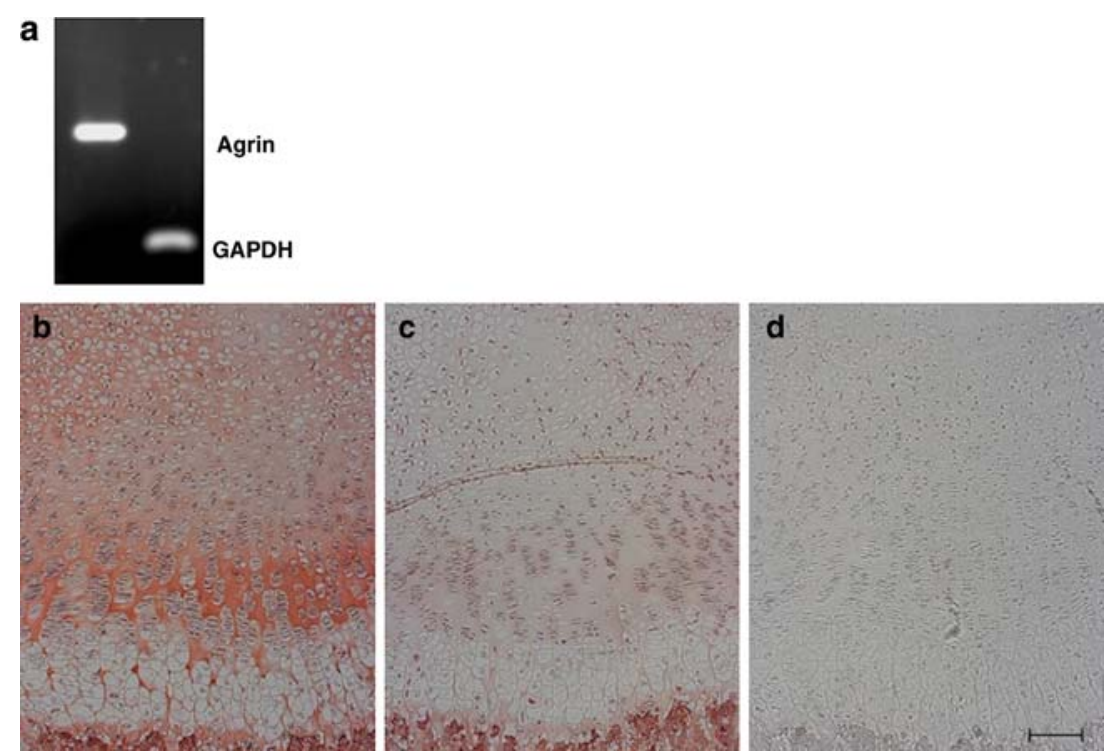

Fig. 3 Agrin is expressed by chondrocytes and is localized in the growth plate of wild-type mice. Using total RNA prepared from isolated murine chondrocytes, agrin expression was detected by means of RT-PCR (a). Sections from paraffin-embedded decalcified tissue were immunostained using agrin-specific antiserum. In the femoral growth plate of 4-day-old wild-type mice agrin was predominantly localized to the zones of prehypertrophic chondrocytes and proliferating chondrocytes (b). Some unspecific staining of metaphyseal bone was also visible in $\mathrm{Tg}_{\mathrm{agrn}}{ }^{-1-}$ mice (c). Primary antibody was omitted in the negative control (d). Bar $100 \mu \mathrm{m}$ collagen type II was already observed prenatally (data not shown).

Apoptosis is not increased in $\mathrm{Tg} / \mathrm{agrn}^{-1-}$ hypertrophic chondrocytes

A possible mechanism accounting for the reduced thickness of the hypertrophic zone in growth plates from $\mathrm{Tg} / \mathrm{agrn}^{-/-}$mice could be an increased apoptosis rate of hypertrophic chondrocytes. We therefore decided to look for apoptosis in growth plate cartilage cells at postnatal day 4. At this developmental stage an effect on the hypertrophic zone can already be observed, yet still sufficient hypertrophic chondrocytes are present for analysis. We used the terminal deoxynucleotide transferase-mediated dUTP nick end labeling (TUNEL) assay to detect DNA strand breaks as an indicator of apoptosis. Apoptosis rates were extremely low at this developmental stage in both types of mice, and no significant differences in the apoptosis rates of hypertrophic chondrocytes could be detected between control and $\mathrm{Tg} / \mathrm{agrn}^{-/-}$mice (Fig. 7).

Decreased chondrocyte proliferation in the growth plates of $\mathrm{Tg} / \mathrm{agrn}^{-1-}$ mice

As apoptosis of hypertrophic chondrocytes was not increased in $\mathrm{Tg}_{\mathrm{agrn}}{ }^{-/}$mice, a decreased differentia- tion of chondrocytes to hypertrophic chondrocytes could account for the observed reduced thickness of the hypertrophic zone. This assumption is also supported by the delayed formation of the secondary ossification center described above (Fig. 5d, e). However, as we did not observe an increase in the thickness of the proliferative zone, we then had to expect decreased proliferation of chondrocytes as well. By immunostaining for the PCNA, we could indeed observe that chondrocyte proliferation is decreased by approximately $50 \%$ in $\mathrm{Tg}_{\mathrm{agrn}} \mathrm{ag}^{--}$mice (Fig. 8).

Chondrocytes express the muscle-specific kinase MuSK

At the NMJ, agrin's postsynapse-inducing activity is mediated by the muscle-specific kinase MuSK (DeChiara et al. 1996). To examine whether MuSK is expressed by chondrocytes as well, we performed RTPCR using primers specific for MuSK. Indeed, PCR products for MuSK were found in these cells (Fig. 9). Furthermore, MuSK expression could also be detected in human chondrocytes (data not shown). Although MuSK does not bind directly to agrin, activation of MuSK is only observed with agrin- $\mathrm{B} / \mathrm{z}^{+}$isoforms (Glass et al. 1996). To determine which agrin isoforms are expressed by chondrocytes, primers flanking the different splice site were used for amplification. Expected 

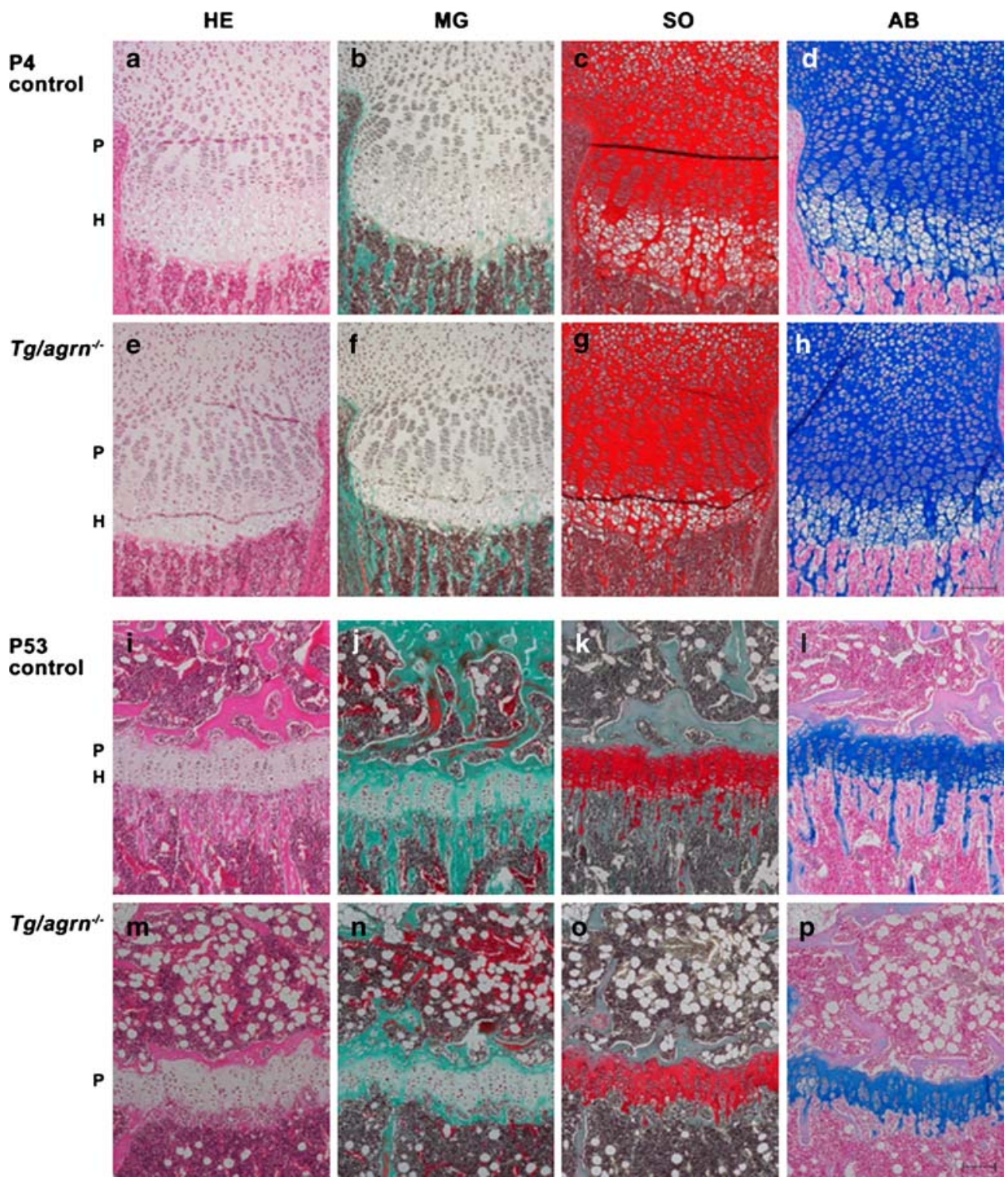

Fig. 4 Histological analysis reveals altered growth plate morpholgy in $\mathrm{Tg}_{\mathrm{agrn}}^{-1-}$ mice. Sections from paraffin-embedded decalcified tissue from 4-day (a-h) and 53-day (i-p) old mice were stained with hematoxylin/eosin (HE: a, e, i, m), by Masson-Goldner staining (MG: b, f, j, n), with safranin O (SO: $\mathbf{c}, \mathbf{g}, \mathbf{k}, \mathbf{o}$ ), and with alcian blue ( $\mathrm{AB}: \mathbf{d}, \mathbf{h}, \mathbf{l}, \mathbf{p})$, respectively. In tibial growth plates from 4-day-old $\mathrm{Tg} / \mathrm{agrn}^{-/-}$mice $(\mathbf{e}-\mathbf{h})$, shortening of the

amplification product sizes are for agrin 14/15 (not alternatively spliced) $184 \mathrm{bp}$; for agrin 19/20 (alternative usage of acceptor site in exon 20) 221 and 248 bp; for agrin 27/29 (alternative splicing of exon 28, y-site) 200 and $212 \mathrm{bp}$; and for agrin 31/34 (alternative splicing of exons 32 and 33, z-site) 184, 208, 217, and 241 bp. As shown in Fig. 9, only transcripts lacking inserts at the $\mathrm{A} / \mathrm{y}$ - and $\mathrm{B} / \mathrm{z}$-site could be detected in chondrocytes. In summary, our results show that both, MuSK and agrin, are expressed in chondrocytes. hypertrophic zone $(\mathrm{H})$ can be seen, while the proliferating zone $(\mathrm{P})$ is essentially unchanged. In the growth plates from 53-day-old Tg/agrn ${ }^{-1-}$ mice, no continuous hypertrophic zone, but rather isolated hypertrophic chondrocytes are present. Safranin $\mathrm{O}$ and alcian blue staining is reduced in the growth plates from $\mathrm{Tg}_{\mathrm{agrn}}{ }^{-}$ - mice at P53 (o, p), indicating a lower glycosaminogycan content. Bar $100 \mu \mathrm{m}$

\section{Discussion}

In this work, we examined the role of agrin in the early postnatal development of mice. As agrin mutant mice die at birth, we used transgenic expression of chick agrin in motor neurons to overcome the lethality. As described elsewhere in detail, the mice used in this study, $\mathrm{Tg} / \mathrm{agrn}^{-/-}$mice, lack all endogenous agrin isoforms outside of the NMJ (I. Ksiazek et al., manuscript in preparation). We find that agrin plays an important 
Fig. 5 No changes in collagen type $\mathrm{X}$ in hypertrophic chondrocytes of $\mathrm{Tg}_{\mathrm{agrn}}{ }^{-/}$mice. Sections from paraffinembedded decalcified tissue of 6-day-old mice were immunostained using collagen type $\mathrm{X}$-specific antiserum. Both wild-type animals $(\mathbf{a}, \mathbf{d})$ and Tg/agrn ${ }^{-/-}$mice $(\mathbf{b}, \mathbf{e})$ exhibit prominent staining of the zone of hypertrophic chondrocytes at the proximal tibia. However, whereas there was a clearly discernible secondary ossification center in wild-type animals (d), this secondary ossification center was absent in $\mathrm{Tg} / \mathrm{agrn}^{-/}$mice (e) at this stage. Primary antibody was omitted in the negative control (c). Bars $50 \mu \mathrm{m}(\mathbf{a}-\mathbf{c})$, $100 \mu \mathrm{m}(\mathrm{d}, \mathbf{e})$

Fig. 6 Collagen type II and aggrecan are slightly reduced in the cartilage matrix from $\mathrm{Tg}_{\text {agrn }}{ }^{-/}$mice. Sections from paraffin-embedded decalcified tissue of 1-day-old (collagen type II staining) and 4-day-old (aggrecan staining) mice were immunostained using collagen type II and aggrecan-specific antiserum, respectively. Primary antibody was omitted in the negative controls. Bar $100 \mu \mathrm{m}$ (aggrecan staining) and $50 \mu \mathrm{m}$ (collagen type II staining), respectively
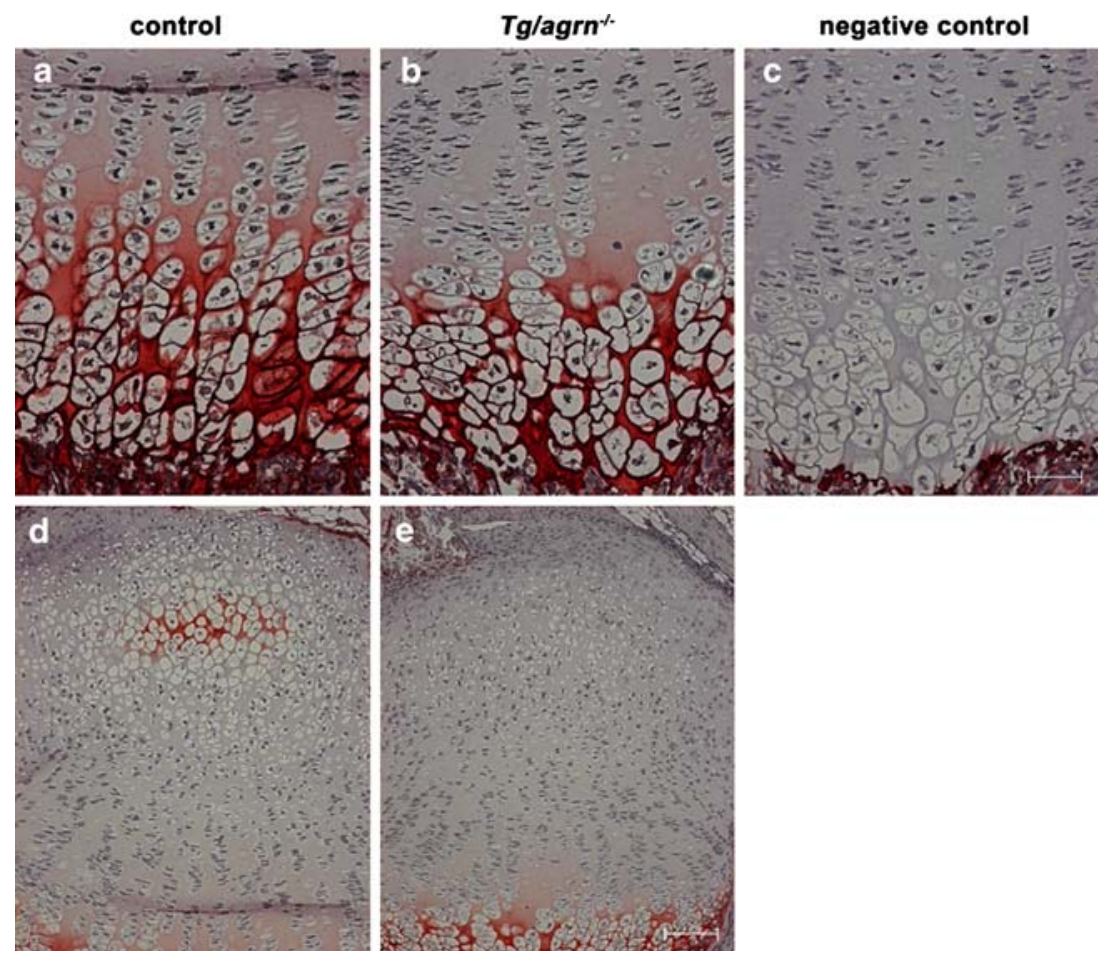

Negative control
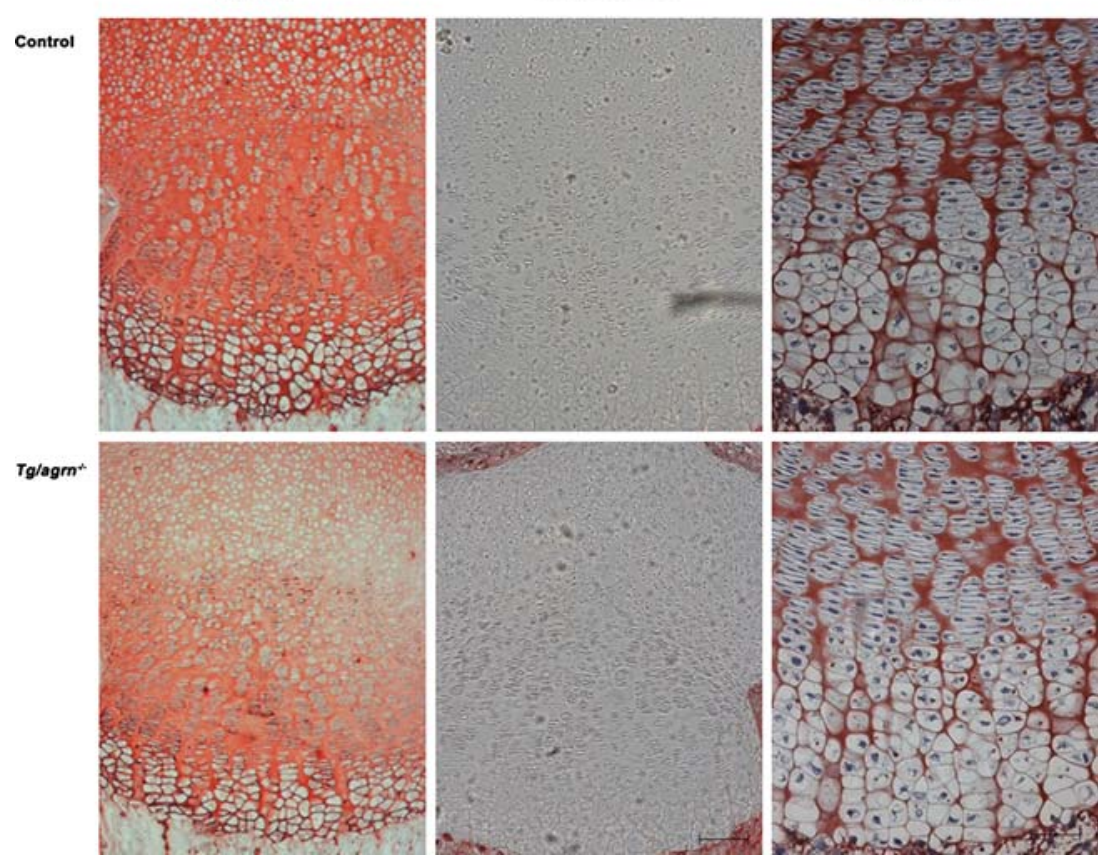

role in skeletal growth and endochondral bone formation. This is a novel finding because development of agrin-deficient embryos has been reported to proceed normally and, except for a slight decrease in embryo size (Serpinskaya et al. 1999), no gross abnormalities in any tissue were reported (Gautam et al. 1996). Moreover, to the best of our knowledge, this work demonstrates for the first time that agrin is expressed in the developing skeletal system.
The most striking effect of agrin deficiency on skeletal development was a marked growth deficiency. Although the weight of $\mathrm{Tg} / \mathrm{agrn}^{-/-}$mice was already reduced at birth, the differences became statistically significant only 4 days after birth and were very pronounced after 2 weeks. Normal growth in mice has been shown to continue until the age of 6 months, resulting in a final weight of approximately $30 \mathrm{~g}$ (Somerville et al. 2004). In contrast, $\mathrm{Tg} / \mathrm{agrn}^{-/-}$mice ceased 
Fig. 7 Hypertrophic chondrocytes in $\mathrm{Tg} / \mathrm{agrn}^{-/-}$mice do not undergo increased apoptosis. Sections from paraffin-embedded decalcified tissue of 4-day-old mice were subjected to TUNEL-staining. Positive controls (POS) were stained after pretreatment with DNase I; in negative controls $(N E G)$, terminal deoxynucleotide transferase was omitted from the incubation mixture. Bar $100 \mu \mathrm{m}$
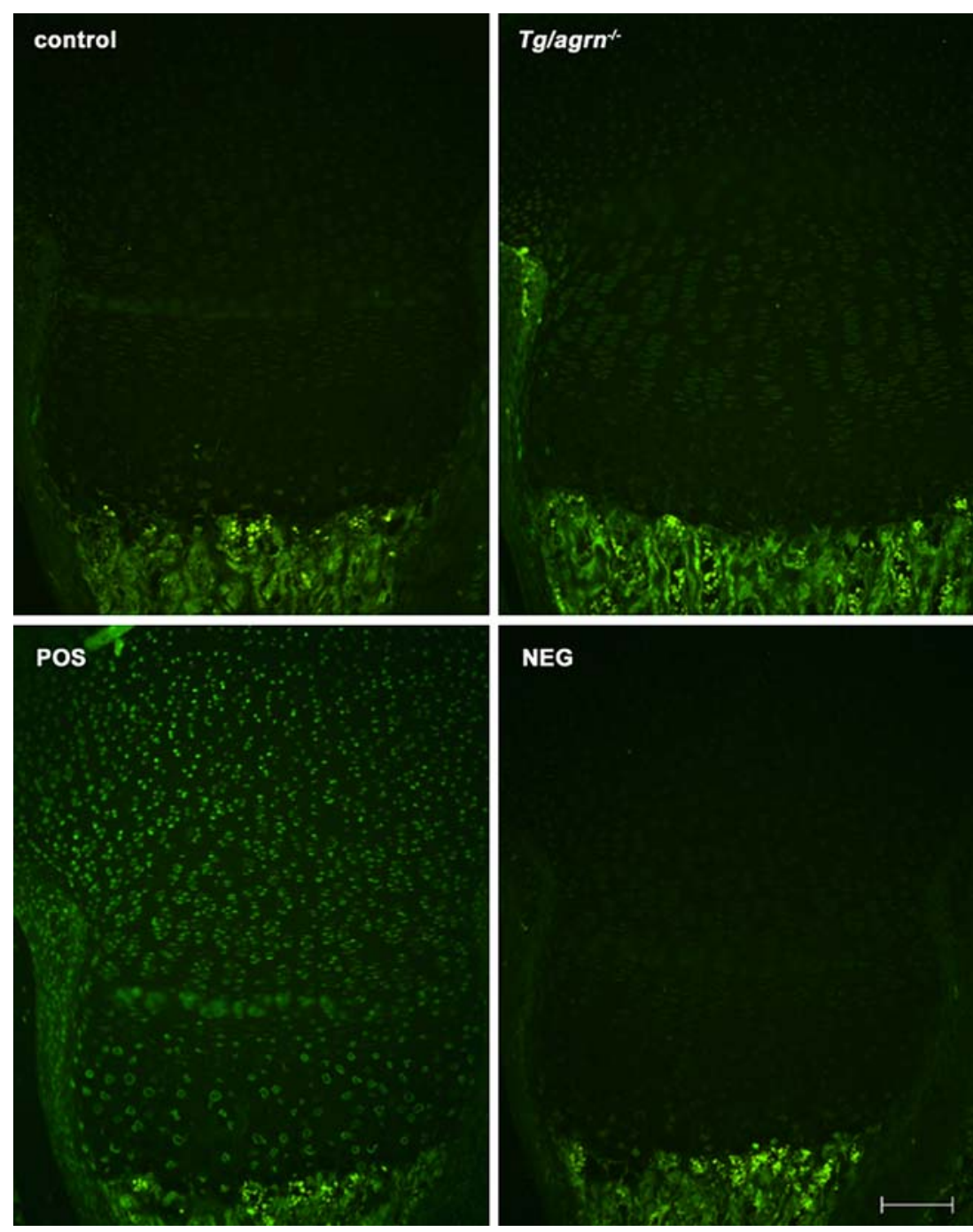

growth after 4 weeks and their final body weight was only $7 \mathrm{~g}$. Restoration of agrin expression in motor neurons of agrin-deficient mice re-established the functionality of neuromuscular synapses, thus allowing the mice to reach an age of up to 3 months. However, we did observe that NMJs in some of the muscles, including the diaphragm, were not innervated properly (I. Ksiazek et al., manuscript in preparation). These data indicate that incomplete restoration of NMJ function could contribute to the increased lethality of $\mathrm{Tg} \mathrm{agrn}^{-1-}$ mice. In bones, the morphological correlate of the growth retardation was a marked compression of the hypertrophic zone in the growth plates. Though the effects of agrin deficiency on growth became most apparent postnatally and growth plates of the proximal tibia appeared morphologically normal at embryonic day 17 (data not shown), alterations in the composition of the cartilage matrix could already be observed prenatally. Morphological changes of the growth plate were also evident only a few days after birth, when the thickness of the hypertrophic zone was reduced by approximately $30 \%$. Thus, although some of the overall growth deficits and the decreased longevity of $\mathrm{Tg} / \mathrm{agrn}^{-/-}$mice might be due to the incomplete restoration of NMJs, the fact that most of the morphological changes in bone can already be observed in young animals strongly argues for a direct role of agrin in bone development.

Growth retardation has been observed in several mutant mice where either structural components of cartilage or regulatory molecules have been targeted. For example, mice deficient of perlecan, which like agrin is a large heparan sulfate proteoglycan, have severe osteochondrodysplasia that manifests itself between embryonic day 15 and birth (Costell et al. 1999). In these mice the size of long bones is reduced by approximately $50 \%$, and growth plates are disorganized, lacking the typical columnar arrangement of hypertrophic chondrocytes. However, both the reduction in size of long bones as well as the morphological 

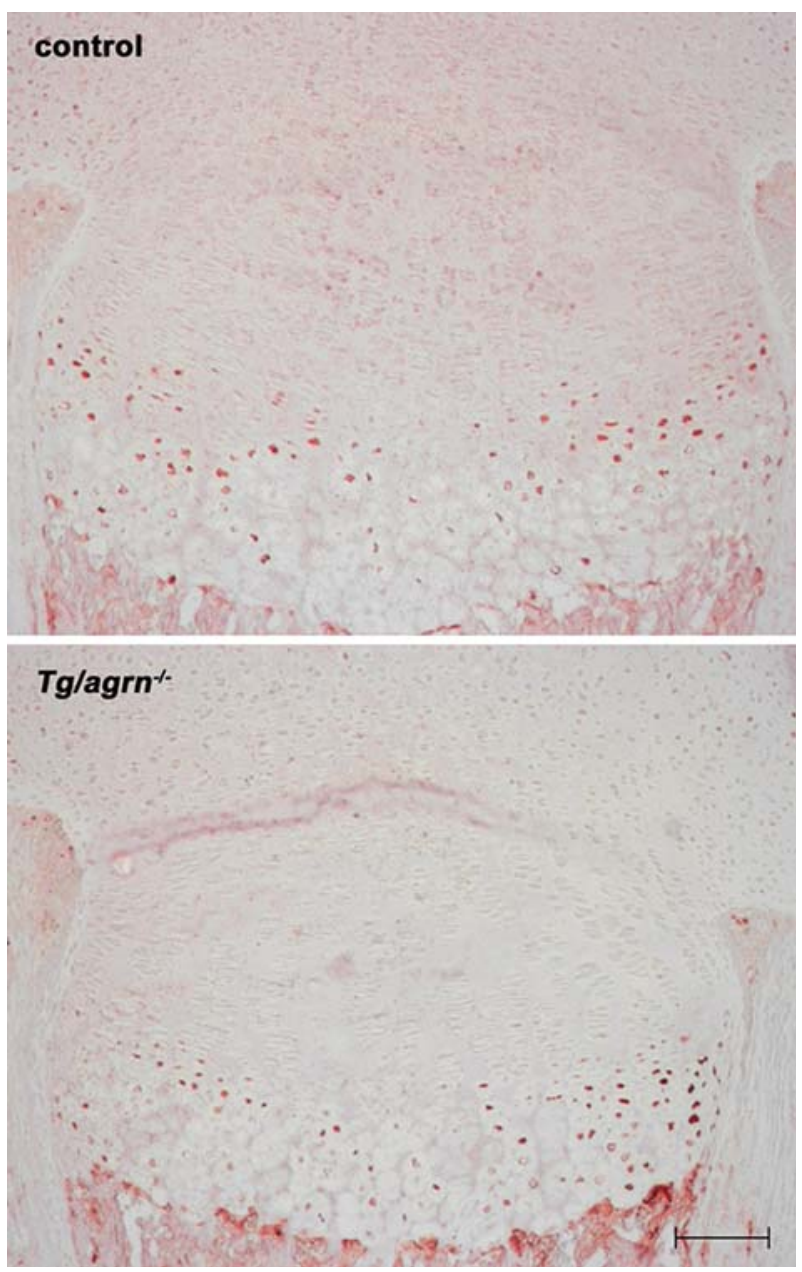

Fig. 8 Lower proliferative activity in chondrocytes from Tg/agrn ${ }^{-1-}$ mice. Sections from paraffin-embedded decalcified tissue of 4-day-old mice were immunostained using PCNA-specific antiserum. Bar $100 \mu \mathrm{m}$

alterations of the growth plates were more severe in the perlecan-deficient mice than in the agrin-deficient mice. Based on the similarities in the skeletal defects of perlecan- and Col2a1-deficient mice (Aszodi et al. 1998), a role for perlecan in the protection of the ECM of cartilage had been proposed, though an increased activity of gelatinases (MMP-2 and MMP-9) could not be demonstrated (Gustafsson et al. 2003). Importantly, our $\mathrm{Tg} / \mathrm{agrn}^{-/-}$mice also exhibit a slightly reduced collagen type II density that is secondary to agrin loss. Other mice mutant in structural components of cartilage that show growth retardation are mice carrying a dominant-negative mutation or a targeted deletion of collagen type $\mathrm{X}$, which is specifically expressed by hypertrophic chondrocytes (Gress and Jacenko 2000; Jacenko et al. 1993; Kwan et al. 1997). In these mice, again in contrast to $\mathrm{Tg} / \mathrm{agrn}^{-1-}$ mice, the compression of the growth plate is confined to zones of resting and proliferating chondrocytes.

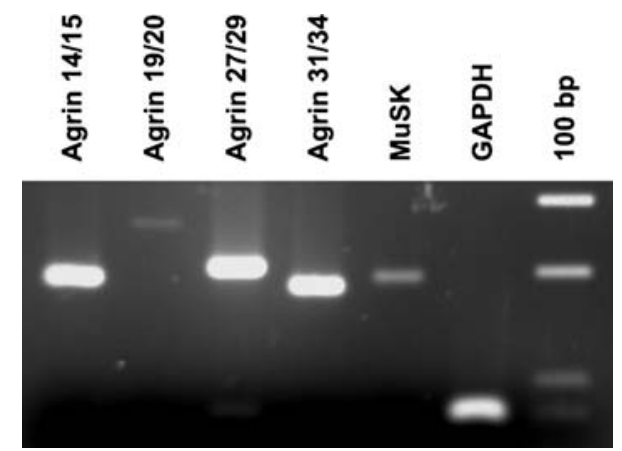

Fig. 9 Chondrocytes express the $z^{-}$isoform of agrin and the muscle-specific kinase MuSK. Using total RNA prepared from isolated murine chondrocytes, MuSK expression (size of the amplification product $193 \mathrm{bp}$ ) was detected by means of RT-PCR. From the size of the amplification product for the z-site (Agrin 31/ 34 ), it is evident that chondrocyte agrin does not contain an insert at this site (expected sizes of the amplification products are $184 \mathrm{bp}$ (no insert), 208 bp, $217 \mathrm{bp}$, and $241 \mathrm{bp}$, respectively)

Mutants impinging on the local regulation of the growth plate affect, for example, Indian hedgehog. Synthesized by prehypertrophic chondrocytes during prenatal development, indian hedgehog acts both in a PTHrPdependent and independent fashion. By inducing the expression of PTHrP in periarticular perichondrial cells, it initiates a negative regulatory loop controlling the differentiation of proliferating chondrocytes (Vortkamp et al. 1996). Analysis of indian hedgehog-deficient mice has also revealed a direct effect on chondrocyte proliferation and osteoblast maturation (St-Jacques et al. 1999). However, due to the rather low expression levels of indian hedgehog in the postnatal growth plate (Iwasaki et al. 1997), the significance of this system for regulation of postnatal bone development has been questioned. Another local regulatory system for the growth plate consists of FGFR3 and its putative ligand FGF-18. For example, mutations that constitutively activate FGFR3 cause achondroplasia, the most common genetic form of dwarfism in humans (Rousseau et al. 1994). Studies using mice that express a constitutively active FGFR3 under the control of regulatory elements from the collagen type II gene revealed that FGFR3 acts primarily by inhibiting chondrocyte proliferation and by slowing chondrocyte differentiation, at least in part by downregulation of the indian hedgehog signaling pathway and of BMP-4 (Naski et al. 1998). Consistent with this dual activity, these mice have reduced zones of proliferating and hypertrophic chondrocytes. $\mathrm{Tg} / \mathrm{agrn}^{-/-}$mice reiterate this phenotype only partially as they have a reduced zone of hypertrophic chondrocytes, but the proliferative zone is not affected.

It is important to note that growth plate morphology is not significantly altered in $\mathrm{Tg} / \mathrm{agrn}^{-/-}$mice until late 
in embryogenesis (E17) and that changes in the hypertrophic zone become more pronounced with age. This indicates that late but not early steps in bone morphogenesis are agrin dependent. From a theoretical point of view, the compression of the hypertrophic zone in our $\mathrm{Tg} / \mathrm{agrn}^{-/-}$mice could result either from a reduced viability of hypertrophic chondrocytes in the absence of agrin or by a reduced differentiation of chondrocytes to hypertrophic chondrocytes. We could not find any evidence for increased apoptosis of hypertrophic chondrocytes in $\mathrm{Tg} / \mathrm{agrn}^{-1-}$ mice, indicating that agrin does not affect chondrocyte viability. However, the observed delayed formation of the secondary ossification center supports the idea that agrin deficiency effects hypertrophic differentiation of chondrocytes. Impaired chondrocyte differentiation should lead to an increasing thickness of the proliferative zone, unless proliferation rates were affected by agrin deficiency, too. Consistent with our observation that proliferative zones were not significantly different in $\mathrm{Tg} / \mathrm{agrn}^{-/}$mice, we found chondrocyte proliferation to be reduced in the absence of agrin. Importantly, in wild type animals agrin localizes predominantly to those zones in the growth plate where proliferation of chondrocytes and differentiation to hypertrophic chondrocytes occurs.

How agrin exerts its effects in the growth plate is not known. At the NMJ, agrin synthesized by presynaptic motor neurons triggers the formation of postsynaptic structures via the muscle-specific receptor tyrosine kinase (MuSK). Though MuSK is expressed by mouse and human chondrocytes (Fig. 9 and H.-J. Hausser, unpublished data), activation of MuSK is believed to require the agrin $\mathrm{B} / \mathrm{z}^{+}$-isoforms of agrin. We could not detect such agrin isoforms in chondrocytes. Whether activation of MuSK could be achieved by agrin isolated from these cells remains to be determined. However, it has recently been shown that agrin synthesized by $\mathrm{T}$ cells also lacks an insert at the $\mathrm{B} / \mathrm{z}^{+}$-site though it has been reported to induce clustering of acetylcholine receptors on cultured myotubes (Khan et al. 2001).

Signaling events downstream of MuSK activation are only poorly understood. However, the recent observation that MuSK interacts with Dishevelled and that this interaction is required for agrin-induced acetylcholine receptor aggregation (Luo et al. 2002) might be of great interest in the context of agrin's effect on skeletal development for two reasons. First, a Frizzledlike cysteine-rich domain is found in the extracellular domain of MuSK and its two closest relatives, ROR1 and ROR2 (Masiakowski and Yancopoulos 1998; Saldanha et al. 1998), and it has therefore been suggested that Wnt-like ligands may bind to these receptors. Indeed, in C. elegans a receptor tyrosine kinase,
LIN-18, has recently been shown to function as a Wnt receptor in parallel to LIN-17/Frizzled (Inoue et al. 2004). Secondly, an increasing number of reports highlight the importance of Wnt-signaling for the regulation of chondrocyte proliferation and differentiation (Church et al. 2002; Yang et al. 2003). Given the similarities of events that depend on proper Wnt-signaling and, as shown in this manuscript, on agrin signaling, it is tempting to speculate that the agrin-MuSK-system and the Wnt-system might interact in the regulation of skeletal development and bone formation. Here, Wntligands might represent the hypothesized accessory factors required for agrin signaling, or, vice versa, agrin might be required for Wnt-signaling. Undoubtedly, this question deserves further investigation.

Acknowledgments The expert technical assistance of Christiane Schulz and Gabi Mettenleiter is gratefully acknowledged. This work was financially supported by the Deutsche Forschungsgemeinschaft (grants HA1652/1-1 and HA1652/1-2), by the Swiss National Science Foundation (to MAR) and the Canton of BaselStadt (to MAR).

\section{References}

Arber S, Han B, Mendelsohn M, Smith M, Jessell TM, Sockanathan S (1999) Requirement of the homeobox gene $\mathrm{Hb} 9$ in the consolidation of motor neuron identity. Neuron 23:659-674

Aszodi A, Chan D, Hunziker E, Bateman JF, Fassler R (1998) Collagen II is essential for the removal of the notochord and the formation of intervertebral discs. J Cell Biol 143:1399_ 1412

Bellus GA, McIntosh I, Smith EA, Aylsworth AS, Kaitila I, Horton WA, Greenhaw GA, Hecht JT, Francomano CA (1995) A recurrent mutation in the tyrosine kinase domain of fibroblast growth factor receptor 3 causes hypochondroplasia. Nat Genet 10:357-359

Burgess RW, Nguyen QT, Son YJ, Lichtman JW, Sanes JR (1999) Alternatively spliced isoforms of nerve- and muscle-derived agrin: their roles at the neuromuscular junction. Neuron 23:33-44

Costell M, Gustafsson E, Aszodi A, Morgelin M, Bloch W, Hunziker E, Addicks K, Timpl R, Fassler R (1999) Perlecan maintains the integrity of cartilage and some basement membranes. J Cell Biol 147:1109-1122

Church V, Nohno T, Linker C, Marcelle C, Francis-West P (2002) Wnt regulation of chondrocyte differentiation. J Cell Sci 115:4809-4818

DeChiara TM, Bowen DC, Valenzuela DM, Simmons MV, Poueymirou WT, Thomas S, Kinetz E, Compton DL, Rojas E, Park JS, Smith C, DiStefano PS, Glass DJ, Burden SJ, Yancopoulos GD (1996) The receptor tyrosine kinase MuSK is required for neuromuscular junction formation in vivo. Cell 85:501-512

Eusebio A, Oliveri F, Barzaghi P, Ruegg MA (2003) Expression of mouse agrin in normal, denervated and dystrophic muscle. Neuromuscul Disord 13:408-415

Ferns MJ, Campanelli JT, Hoch W, Scheller RH, Hall Z (1993) The ability of agrin to cluster AChRs depends on alternative splicing and on cell surface proteoglycans. Neuron 11:491-502 
Gautam M, Noakes PG, Moscoso L, Rupp F, Scheller RH, Merlie JP, Sanes JR (1996) Defective neuromuscular synaptogenesis in agrin-deficient mutant mice. Cell 85:525-535

Gesemann M, Denzer AJ, Ruegg MA (1995) Acetylcholine receptor-aggregating activity of agrin isoforms and mapping of the active site. J Cell Biol 128:625-636

Girkontaite I, Frischholz S, Lamm P, Wagner K, Swoboda B, Aigner T, von der Mark K (1996) Immunolocalization of type $\mathrm{X}$ collagen in normal fetal and adult osteoarthritic cartilage with monoclonal antibodies. Matrix Biol 15:231-238

Glass DJ, Bowen DC, Stitt TN, Radziejewski C, Bruno J, Ryan TE, Gies DR, Shah S, Mattsson K, Burden SJ, DiStefano PS, Valenzuela DM, DeChiara TM, Yancopoulos GD (1996) Agrin acts via a MuSK receptor complex. Cell 17:513-523

Goldner J (1938) A modification of the Masson trichrome technique for routine laboratory purposes. Am J Pathol 14:237243

Gress CJ, Jacenko O (2000) Growth plate compressions and altered hematopoiesis in collagen $\mathrm{X}$ null mice. $\mathrm{J}$ Cell Biol 149:983-993

Groffen AJ, Ruegg MA, Dijkman H, van de Velden TJ, Buskens CA, van den Born J, Assmann KJ, Monnens LA, Veerkamp JH, van den Heuvel LP (1998) Agrin is a major heparan sulfate proteoglycan in the human glomerular basement membrane. J Histochem Cytochem 46:19-27

Gustafsson E, Aszodi A, Ortega N, Hunziker EB, Denker HW, Werb Z, Fassler R (2003). Role of collagen type II and perlecan in skeletal development. Ann N Y Acad Sci 995:140-150

Inoue T, Oz HS, Wiland D, Gharib S, Deshpande R, Hill RJ, Katz WS, Sternberg PW (2004) C. elegans LIN-18 is a Ryk ortho$\log$ and functions in parallel to LIN-17/Frizzled in Wnt signaling. Cell 118:795-806

Iwasaki M, Le AX, Helms JA (1997) Expression of indian hedgehog, bone morphogenetic protein 6 and gli during skeletal morphogenesis. Mech Dev 69:197-202

Jacenko O, LuValle PA, Olsen BR (1993) Spondylometaphyseal dysplasia in mice carrying a dominant negative mutation in a matrix protein specific for cartilage-to-bone transition. $\mathrm{Na}-$ ture 365:56-61

Karaplis AC (2002) Embryonic development of bone and the molecular regulation of intramembranous and endochondral bone formation. In: Bilezikian JP, Raisz LG, Rodan GA (eds) Principles of bone biology, vol 1, 2nd edn. Academic. San Diego, pp 33-58

Khan AA, Bose C, Yam LS, Soloski MJ, Rupp F (2001) Physiological regulation of the immunological synapse by agrin. Science 292:1681-1686

Kronenberg HM (2003) Developmental regulation of the growth plate. Nature 423:332-336

Kwan KM, Pang MK, Zhou S, Cowan SK, Kong RY, Pfordte T, Olsen BR, Sillence DO, Tam PP, Cheah KS (1997) Abnormal compartmentalization of cartilage matrix components in mice lacking collagen $\mathrm{X}$ : implications for function. J Cell Biol 136:459-471

Lieth E, Cardasis CA, Fallon JR (1992) Muscle-derived agrin in cultured myotubes: expression in the basal lamina and at induced acetylcholine receptor clusters. Dev Biol 149:41-54

Lin W, Burgess RW, Dominguez B, Pfaff SL, Sanes JR, Lee K-F (2001) Distinct roles of nerve nd muscle in postsynaptic differentiation of the neuromuscular synapse. Nature 410:1057-1064

Luo ZG, Wang Q, Zhou JZ, Wang J, Luo Z, Liu M, He X, Wynshaw-Boris A, Xiong WC, Lu B, Mei L (2002) Regulation of AChR clustering by Dishevelled interacting with MuSK and PAK1. Neuron 35:489-505
Masiakowski P, Yancopoulos GD (1998) The Wnt receptor CRD domain is also found in MuSK and related orphan receptor tyrosine kinases. Curr Biol 8:R407

McMahan UJ (1990) The agrin hypothesis. Cold Spring Harb Symp Quant Biol 55:407-418

Naski MC, Colvin JS, Coffin JD, Ornitz DM (1998) Repression of hedgehog signaling and BMP4 expression in growth plate cartilage by fibroblast growth factor receptor 3. Development 125:4977-4988

Nitkin RM, Smith MA, Magill C, Fallon JR, Yao YM, Wallace BG, McMahan UJ (1987) Identification of agrin, a synaptic organizing protein from Torpedo electric organ. J Cell Biol 105:2471-2478

O'Connor LT, Lauterborn JC, Gall CM, Smith MA (1994) Localization and alternative splicing of agrin mRNA in adult rat brain: transcripts encoding isoforms that aggregate acetylcholine receptors are not restricted to cholinergic regions. J Neurosci 14:1141-1152

Rousseau F, Bonaventure J, Legeai-Mallet L, Pelet A, Rozet JM, Maroteaux P, Le Merrer M, Munnich A (1994) Mutations in the gene encoding fibroblast growth factor receptor-3 in achondroplasia. Nature 371:252-254

Ruegg MA, Tsim KW, Horton SE, Kroger S, Escher G, Gensch EM, McMahan UJ (1992) The agrin gene codes for a family of basal lamina proteins that differ in function and distribution. Neuron 8:691-699

Rupp F, Ozcelik T, Linial M, Peterson K, Francke U, Scheller R (1992) Structure and chromosomal localization of the mammalian agrin gene. J Neurosci 12:3535-3544

Saldanha J, Singh J, Mahadevan D (1998) Identification of a Frizzled-like cysteine rich domain in the extracellular region of developmental receptor tyrosine kinases. Protein Sci 7:16321635

Serpinskaya AS, Feng G, Sanes JR, Craig AM (1999) Synapse formation by hippocampal neurons from agrin-deficient mice. Dev Biol 205:65-78

Somerville JM, Aspden RM, Armour KE, Armour KJ, Reid DM (2004) Growth of C57BL/6 mice and the material and mechanical properties of cortical bone from the tibia. Calcif Tissue Int 74:469-475

St-Jacques B, Hammerschmidt M, McMahon AP (1999) Indian hedgehog signaling regulates proliferation and differentiation of chondrocytes and is essential for bone formation. Genes Dev 13:2072-2086

Tavormina PL, Shiang R, Thompson LM, Zhu YZ, Wilkin DJ, Lachman RS, Wilcox WR, Rimoin DL, Cohn DH, Wasmuth JJ (1995) Thanatophoric dysplasia (types I and II) caused by distinct mutations in fibroblast growth factor receptor 3. Nat Genet 9:321-328

Thaler J, Harrison K, Sharma K, Lettieri K, Kehrl J, Pfaff SL (1999) Active suppression of interneuron programs within developing motor neurons revealed by analysis of homeodomain factor HB9. Neuron 23:675-687

Van der Eerden BCJ, Karperien M, Witt JM (2003) Systemic and local regulation of the growth plate. Endocr Rev 24:782-801

Vanky P, Brockstedt U, Hjerpe A, Wikström B (1998) Kinetic studies on epiphyseal growth cartilage in the normal mouse. Bone 22:331-339

Vortkamp A, Lee K, Lanske B, Segre GV, Kronenberg HM, Tabin CJ (1996) Regulation of rate of cartilage differentiation by Indian hedgehog and PTH-related protein. Science 273:613-622

Yang Y, Topol L, Lee H, Wu J (2003) Wnt5a and Wnt5b exhibit distinct activities in coordinating chondrocyte proliferation and differentiation. Development 130:1003-1015 